Journal of Advanced Research in Fluid Mechanics and Thermal Sciences

\title{
Investigation of Thermal, Mechanical and Transport Properties of Ultra- Lightweight Foamed Concrete (ULFC) Strengthened with Alkali Treated Banana Fibre
}

\author{
Mohammed Hassan Nensok ${ }^{1}$, Md Azree Othuman Mydin ${ }^{1,}{ }^{*}$, Hanizam Awang ${ }^{1}$ \\ 1 School of Housing, Building and Planning, Universiti Sains Malaysia, 11800, Penang, Malaysia
}

\section{ARTICLE INFO}

\section{Article history:}

Received 25 March 2021

Received in revised form 22 June 2021

Accepted 24 June 2021

Available online 16 August 2021

\section{Keywords:}

Foamed concrete; thermal properties; banana fibre; alkali treatment

\section{ABSTRACT}

Traditionally, Ultralightweight Foam Concrete (ULFC) is primarily used to replace filling excavations, ditch restoration and underground channels, because of their high porosity, water absorption and low strength. Yet, ULFC is characterized by excellent thermal properties and could be an alternative for sustainable energy-efficient building material. This study investigates the properties of an ULFC strengthened with alkalitreated banana fibre. The low density ULFC of $600 \mathrm{~kg} / \mathrm{m}^{3}$ was fabricated and strengthened with alkali-treated banana fibre. Fibre volume fraction of $0.25 \%, 0.35 \%$, $0.45 \%$ and $0.55 \%$ were compared to the unreinforced specimens, serving as the control specimen (no fibre addition). Mix proportioning of 1:1.5:0.45 of cement, sand, and water was respectively adopted throughout the mix. The alkali treated banana fibre strengthened ULFC was tested for compressive strength, sorptivity and thermal properties. Morphology of the treated fibre and ULFC composites was studied using SEM micrograph. The result depicts that ULFC exhibited the optimum compressive strength of $1.1604 \mathrm{~N} / \mathrm{mm}^{2}$ with the fibre volume fraction of $0.35 \%$. Sorptivity or rate of water absorption was testified to upsurge, after 24 hours duration at fibre volume fraction of $0.55 \%$, recording a $56.12 \%$ increment compared to the control specimen. The finding displays that at the highest-fibre volume fraction of $0.55 \%$, thermal conductivity and diffusivity decrease by $13.17 \%$ and $28.16 \%$, correspondingly, whiles the specific heat capacity increases to $37.17 \%$ all compared with unreinforced specimens. SEM images reveal that the presence of lumen and the nature of porous and fibrous alkali-treated banana fibre. Hence, it is endorsed that ULFC produced with alkali-treated banana fibre should be utilized as an infill material for composite system.

\section{Introduction}

Nowadays, there is a continuous rise in environmental temperature worldwide due to global warming and climate change. This is because of the excessive increase in the $\mathrm{CO}_{2}$ emission caused chiefly due to industrialization, transportation, greenhouse gas emission, and disruption of the natural eco-system for developmental purposes. This is of great concern to the world, especially in

\footnotetext{
* Corresponding author.

E-mail address: azree@usm.my
}

https://doi.org/10.37934/arfmts.86.1.123139 
the tropical developing countries such as South-East Asea, South America, and most of Africa. Very high temperatures between $20 \pm 5^{\circ} \mathrm{C}-40 \pm 5^{\circ} \mathrm{C}$ traditionally characterize these countries. Hence, with the escalating increase in global warming caused by climate change and an increase in ambient temperature due to tropical weather conditions, there is a great demand for energy consumption by air conditioning systems. This calls for a strong need to adopt measures to reduce energy consumption by improving buildings' thermal comfort constructed in such regions.

Furthermore, most of the countries found within these regions are under-developed or developing countries. For instance, India, Indonesia, Philippines, Thailand, Brazil, Chile, Ecuador, Mali, Niger, Nigeria, Malaysia, etc. characterized by enormous energy or power shortages, and the escalating high ambient environmental temperature. The present population of these countries is reported to be $40 \%$ of the world population. Besides, these countries are continuously abysmally getting overpopulated day in, day out. Hence, a situation of increasing housing demand where power or electrical energy is a mirage persists. The best solution or approach to this problem is developing and using sustainable construction practices and materials.

Generally, there is a massive demand for energy worldwide, and the regular competition for this energy is between industrial and domestic consumers. The production of this energy, in most cases, contributes to environmental pollution and climate change. As a result, reducing the rise in energy usage and greenhouse gas emissions caused by the world's rising population is an issue worth exploring. Therefore, adopting sustainable construction practices in the production of construction materials is strongly recommended. One good option is to produce construction materials with low thermal conductivity value, such as clay bricks, hollow bricks, and blocks, low-density interlocking bricks, interlocking wood brick, lightweight concrete blocks, lightweight foam concrete, etc.

One of the most exciting energy-efficient materials recently used in construction today, which is lightweight, quickly produced, sustainable, affordable, flexible in density, is the lightweight foam concrete. According to Elshahawi and Hückler [1], Lightweight foamed concrete (LFC) has a flexible density range between $400-1900 \mathrm{~kg} / \mathrm{m}^{3}$. LFC of density between $800-1900 \mathrm{~kg} / \mathrm{m}^{3}$ is considered structural lightweight foamed concrete, while LFC of density from $400-800 \mathrm{~kg} / \mathrm{m}^{3}$ is known as ultralight foamed concrete (ULFC). The former definition is non-structural LFC, and because of it, lightweight possesses a lower thermal conductivity value than the latter. This paper will focus mainly on the ULFC with emphases on the strength, transport, and thermal properties. ULFC is characterized by very low density, high porosity, larger void sizes, excellent sound and thermal insulation property, and fire resistance.

Though, one of the major drawbacks of this lightweight concrete is its low in strength. compared to normal-weight concrete. This is because a coarse aggregate in ULFC is replaced by $50-80 \%$ of foam or air bubbles produced using foaming agents. A lack of coarse aggregate makes ULFC very brittle, fragile, and possess insufficient compressive strength (ranging between 0.5-2 MPa). It has been reported that the flexural strength of $\mathrm{FC}$ is about 7-10 times lower than the compressive strength [2]. Low compressive strength makes ULFC exhibit a high tendency for flexural cracks. To arrest this weakness of flexural cracks, common with ULFC, and at the same time maintain its perfect thermal property, banana fibre is used in this study. Banana fibre is a natural fibre derived from the banana plant's pseudo stem, a vast fruit plant commonly planted and eaten worldwide.

The choice of banana fibre instead of synthetic fibre such as glass, polypropylene, steel, etc., is because banana fibre is natural and sustainable, readily available in most tropical, developing countries and worldwide. After the banana fruit harvest, the pseudo stem is left on the farm as an agricultural wase. For everyone tone of harvested banana fruit, there is two tons of banana pseudo stem waste left in the farm to rots or decompose year in year out. The production of banana fibre leads to the release of $\mathrm{O}_{2}$ and absorption of $\mathrm{CO}_{2}$ (Photosynthesis) in the environment compared to 
other synthetic fibres whose production releases a lot of $\mathrm{CO}_{2}$ in the background. Banana fibre is biodegradable, recyclable and a lightweight fibre, compared to glass and steel fibre. As a result, banana plant fibres are environmentally friendly and could be used to enhance the mechanical and thermal properties of ULFCs.

Research on the utilization of bananas in concrete composites is not new. Over a decade now, there have been many research efforts on the production of cement/mortar/concrete composites to determine primarily mechanical and durability properties of banana fibre reinforced composites [35]. Similar research efforts are recently undertaken, focusing mainly on the mechanical properties and material characterization [6,7]. However, there is a lack of in-depth awareness of the thermophysical behaviour of cement/mortar/concrete composites strengthened with banana fibre. The knowledge gap is vacant in regular cement composites as well as ultra-lightweight cement composites.

However, an attempt by researchers in LFC shows some efforts on the determination of thermal and durability properties of LFC reinforced with natural and synthetic fibres. Othuman Mydin et al., [8] undertook research efforts using coconut fibre in LFC of density $1350 \mathrm{~kg} / \mathrm{m}^{3}$. The coconut fibre dosage was varied per the mix's total weight volume at $0.2 \%$ and $0.4 \%$. This study reveals that the addition of coconut fibre in LFC reduces thermal diffusivity and conductivity but increases the composites' specific heat capacity. Similar research efforts were conducted using steel fibre [9]. In this study, as expected of steel fibre, the LFC composites' thermal conductivity and thermal diffusivity increase with an increase in the steel fibre dosage and the control. These two results mean that while coconut plant fibre (natural fibre) improves LFC's thermal properties, steel fibre (synthetic fibre) helps lessen LFC's thermal performance. Awang and Ahmad [10] undertook a comparative investigation of synthetic and natural fibres at fibre dosages of $0.25 \%$ and $0.40 \%$. The fibres investigated in LFC composites of $1000 \mathrm{~kg} / \mathrm{m}^{3}$ are steel, glass, oil palm, kenaf and polypropylene fibres. This study reveals that polypropylene fibre performs better in terms of thermal property, followed by kenaf fibre, oil palm fibre, glass fibre, and lastly, steel fibre in that order. The study also indicates that the thermal performances of these composites improve with an increase in fibre content. Recent research efforts by Raj et al., [11] compare the performance of LFC composites reinforced with coir fibre, polyvinyl alcohol fibre, and the hybrid of the two threads. The study results reveal that LFC reinforced with coir fibre performs better than that reinforced with polyvinyl alcohol fibre, which serves better than LFC strengthened with the two fibres' hybrid composites

In line with the above, this study focuses on determining the strength, capillary rise of water and thermal properties of ULFC strengthened with banana fibre. ULFC density of $600 \mathrm{~kg} / \mathrm{m}^{3}$ was developed with different dosages of fibre and the composites' strength, transport, and thermal properties were studied. Physical properties such as density and SEM micrograph are essential parameters in explaining the thermal property of LFC. They are therefore unified to give a better understanding of this thermal insulating building material. The study also investigates the influence of high matrix porosity on compressive strength and, finally, the thermal performance of ULFC.

\section{Methodology}

\subsection{Materials}

Ordinary Portland cement (OPC) grade 53 complying with BS EN 197-1 [12] was used as the study's binder. The cement has a specific gravity and a standard consistency of 2.94 and 29\%, respectively. The chemical composition of the cement used in the study is given in Table 1. River sand was obtained from a nearby river and supplied to the laboratory. The river sand was dried in the open sun for 72 hours and sieved with a $1.18 \mathrm{~mm}$ sieve. The specific gravity of the river sand and fineness 
modulus was 2.6 and 2.01, respectively. The mixing was conducted with Ordinary portable tap water suitable for drinking. The $p^{H}$ value of the water was measured and recorded as 6.97. The banana fibre was obtained from the banana plant at a farm in Penang, Malaysia. The cut trees were further chopped into smaller pieces and process directly using a mechanical refiner in the School of Industrial Technology (SIT), USM (Refer to Table 2 for the chemical composition of the fibre). The natural process fibre was subjected to $6 \%$ alkali treatment using $\mathrm{NaOH}$ pellets 24 hours before being used in the study (Refer to Figure 1 for alkali-treated banana fibre). Table 3 shows the mechanical and physical properties of the alkali-treated banana fibre used in the study.

The foamed concrete was produced using a foam generator and a foaming agent, all locally produced in Malaysia with a trademark name Portafoam PM1 and Noraite PA-1, respectively. Noraite PA-1 is a protein foaming agent mixed with tap water by a ratio of 1:30 (Noraite PA-1: Water). After mixing the agent, it was then connected through a rubber hose into the foaming machine. With the aid of gas pressure of about 450kpa and connected to a source of power, the foaming machine forcefully produced a stable foam of a density of 60-80 gram/litre.

Table 1

Chemical property of cement

\begin{tabular}{lll}
\hline No. & Oxides & Percentage Quantity (\%) \\
\hline 1 & Calcium oxide $\mathrm{Ca}_{2} \mathrm{O}$ & 65.95 \\
2 & Aluminium $\mathrm{Oxide}_{2} \mathrm{Al}_{3}$ & 5.84 \\
3 & Silica Oxide $\mathrm{SiO}_{2}$ & 16.84 \\
4 & Ferric Oxide $\mathrm{Fe}_{2} \mathrm{O}_{3}$ & 2.64 \\
5 & Magnesium Oxide $\mathrm{MgO}$ & 1.49 \\
6 & Sulphur Oxide & 2.76 \\
7 & Phosphorus Oxide & 0.08 \\
8 & Potassium Oxide K2O & 0.87 \\
9 & Loss of Ignition & - \\
\hline
\end{tabular}

Table 2

Chemical composition of raw banana fibre

\begin{tabular}{lllllll}
\hline Fibre type & Lignin & Hemicellulose & Cellulose & Extractive & Ash content & Moisture \\
\hline Banana & 5.10 & 18.60 & 63.20 & 1.40 & 1.02 & 10.00 \\
\hline
\end{tabular}

Table 3

Physical and mechanical property of alkali treated banana fibre

\begin{tabular}{lll}
\hline S/No & Parameters & Properties \\
\hline 1 & Average length $(\mathrm{mm})$ & $30-50$ \\
2 & Diameter $(\mathrm{mm})$ & 0.189 \\
3 & Density $(\mathrm{g} / \mathrm{cc})$ & 1.35 \\
4 & Tensile strength $(\mathrm{MPa})$ & 487 \\
5 & Young Modulus $(\mathrm{GPa})$ & 28.7 \\
6 & Elongation at break $(\%)$ & 10.1 \\
\hline
\end{tabular}




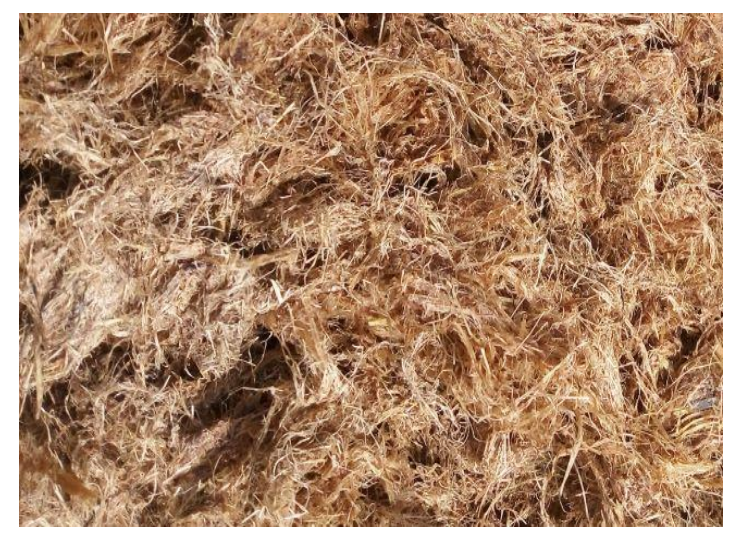

Fig. 1. Alkali treated banana fibre

\subsection{ULFC Composites Production}

Banana fibre reinforced FC was produced in the laboratory using the water/binder (W/B) ratio of 0.45 and binder/filler ratio 1:1.5. The entire materials, including the fibre, were mix using a concrete mixer in the laboratory in stages after measuring all components of the mix. Table 4 below shows the summary of the mix designed for each batch mix produced in this study. The percentage fibre addition in the mix was based on the total volume weight of the mix. Batch mix were identified as follows: $0.00 \% \mathrm{CTR}, 0.25 \% \mathrm{BF}, 0.35 \% \mathrm{BF}, 0.45 \% \mathrm{BF}, 0.55 \% \mathrm{BF}$. Where $0.00 \%-0.55 \%$ depicts the percentage fibre in each mix, CTR stands for the control mix, and BF refers to the alkali-treated banana fibre. Materials mixing started with introducing first the measured sand into the mixer, followed by the cement. Sand and cement were mixed for $3 \pm 2$ minutes or until homogeneity. 2/3 of the measured mixing water was then added and given $3 \pm 2$ minutes to mix properly. The remaining water was then poured into the mix, followed by the banana fibre, and the mix was again given $3 \pm 2$ minutes to mix to homogeneity properly. The mix was checked for workability using the open-ended cylinder. If the base mix's workability is not up to $180-240 \mathrm{~mm}$, additional water was added to make the mortar mix consistent.

After achieving good workability, the foam produced from foaming machine of the density of 6080gram/litre was introduced into mix gradually based on quantity calculated and given in Table 4 . Constant measurement of the ULFC composites density was necessary when gradually introducing the foam until the calculated wet or plastic density was achieved. A 1-liter cylindrical cup was used for this exercise. Since the dry target density of the ULFC was $600 \mathrm{Kg} / \mathrm{m}^{3}$, the wet or plastic density should be $600 \pm 120 \mathrm{Kg} / \mathrm{m}^{3}=700 \pm 20 \mathrm{Kg} / \mathrm{m}^{3}$. After mixing to the required density, the batches were cast on various mould samples 24 hours before demoulding. Test samples were cured by moist curing using plastic wrapping until the date of the test. The specimens were then tested at the curing ages of 7, 14 and 28 days.

Table 4

Mixture proportioning of ULFC composites

\begin{tabular}{llllllll}
\hline Code & W/B ratio & B/F ratio & Fibre $(\mathrm{Kg})$ & Binder $(\mathrm{Kg})$ & Filler $(\mathrm{Kg})$ & Water $(\mathrm{Kg})$ & Foam (Litre) \\
\hline CTRL & 0.45 & $1: 1.5$ & - & 21.87 & 32.81 & 9.84 & 63 \\
$0.25 \mathrm{BF}$ & 0.45 & $1: 1.5$ & 0.161 & 21.87 & 32.81 & 9.84 & 63 \\
$0.35 \mathrm{BF}$ & 0.45 & $1: 1.5$ & 0.226 & 21.87 & 32.81 & 9.84 & 63 \\
$0.45 \mathrm{BF}$ & 0.45 & $1: 1.5$ & 0.290 & 21.87 & 32.81 & 9.84 & 63 \\
$0.55 \mathrm{BF}$ & 0.45 & $1: 1.5$ & 0.355 & 21.87 & 32.81 & 9.84 & 63 \\
\hline
\end{tabular}




\subsection{Experimental Test Methods}

\subsubsection{Test for compressive strength and density of hardened composites}

The compressive strength of materials was conducted using cube specimens with the dimension of $100 \mathrm{~mm} \times 100 \mathrm{~mm} \times 100 \mathrm{~mm}$. The test was undertaken in compliance with BS EN 12390-3 [13]. Before testing for the compressive strength, cube samples were first measured for oven-dry density. The hardened test specimen density determination was in line with BS EN 12390-7 [14].

\subsubsection{Sorptivity test}

The determination of the rate of water absorption, sometimes referred to as the sorptivity or capillary rise in the water on the ULFC test specimen, was conducted as per ASTM C 1403-15 [15]. Three ULFC test specimens of dimension $50 \times 50 \times 50 \mathrm{~mm}$ cube were produced and used for this test, and they are average recorded as the samples' sorptivity. This test's samples were first cast and moist cured for 28 days before subjected to oven drying for $72 \pm 2$ hours or until the equal weight was recorded. Test samples surface length $\left(L_{1}\right)$ and width $\left(L_{2}\right)$ are then measured using a calliper. The initial weight of the dry samples was then recorded as $W_{0}$. The test samples' top surface was placed on the water surface through the depth of $3 \pm 5 \mathrm{~mm}$ using wedge support in the water bath. The partially saturated weight of the test samples was then measured and recorded at an interval of $15 \pm 0.5$ minutes, $60 \pm 2$ minutes, $240 \pm 10$ minutes, and $1440 \pm 15$ minutes. The weight was measured for each test specimen and recorded as $W_{T}$, where $T$ is the measurement time in minutes. Hence, the rate of water absorption written as $A_{T}$ is given by

Sorptivity $=A_{T}=\frac{W T-W o \times 10000}{L 1 \times L 2}$

\subsubsection{Thermal conductivity, diffusivity, and specific heat capacity test}

Thermal conductivity, diffusivity, and specific heat capacity of ULFC reinforced with alkali-treated banana fibre was conducted using the method described by ISO 22007-2 [16]. The test was conducted using a hot disc thermal constant analyser. The test method is based on the transient plane source (TPS) method. In this study, the test was conducted in the school of material engineering, USM, using the thermal conductivity meter called the Hot Disk Thermal Constant Analyser TPS $2500 \mathrm{~S}$. This thermal conductivity meter can measure within a short period the thermal conductivity, thermal diffusivity, and specific heat capacity of material all at once and gives the reading directly. Besides, TPS $2500 \mathrm{~S}$ can measure any material parameters, e.g., solid, liquid, pastes, foams, etc. Table 5 gives the specification of the TPS $2500 \mathrm{~S}$ thermal conductivity meter used in this research. Figure 2 demonstrates a typical setup for the thermal conductivity meter in the laboratory.

The test samples for each test were obtained after 28 days of curing the batch mixes using carefully cut samples of $70 \times 40 \times 20 \mathrm{~mm}$. After cutting the samples in pairs, the samples are smoothened, sandpapered, blown with the air blower, and dried. Two samples of identical dimensions are first put in the oven at $75 \pm 5^{\circ} \mathrm{C}$ for 72 hours or until constant weight to remove the moisture in them altogether. The pairs of samples are prepared according to the code batches given in Table 4. Two samples of identical dimensions are used to sandwich a constant thermal analyser sensor. 


\section{Table 5}

Specification for the hot disk thermal constant analyser TPS $2500 \mathrm{~S}$

\begin{tabular}{lll}
\hline No. & Property & Specification \\
\hline 1 & Thermal conductivity & $0.005-1800 \mathrm{~W} / \mathrm{m} \mathrm{K}$ \\
2 & Thermal diffusivity & $0.1-1200 \mathrm{~mm}^{2} / \mathrm{sec}$ \\
3 & Specific heat & Up to $5 \mathrm{MJ} / \mathrm{m}^{3} \mathrm{~K}$ \\
4 & Temperature range & $-235^{\circ} \mathrm{C}-1000^{\circ} \mathrm{C}$ \\
5 & Measurement time & $1-1280 \mathrm{~second}$ \\
6 & Biggest sample size & Unlimited \\
7 & Smallest sample size & $0.5 \mathrm{~mm} \times 2 \mathrm{~mm}$ for bulk testing \\
& & $0.1 \mathrm{~mm} \times 10 \mathrm{~mm}$ for slab testing \\
& & $3 m m \times 5 \mathrm{~mm}$ for one dimensional testing \\
8 & Power requirement & Adjustable to any line voltage in the region \\
9 & Sensor type & All Kapton, Mica and Teflon sensors \\
10 & Accuracy & Greater than $5 \%$ \\
\hline
\end{tabular}

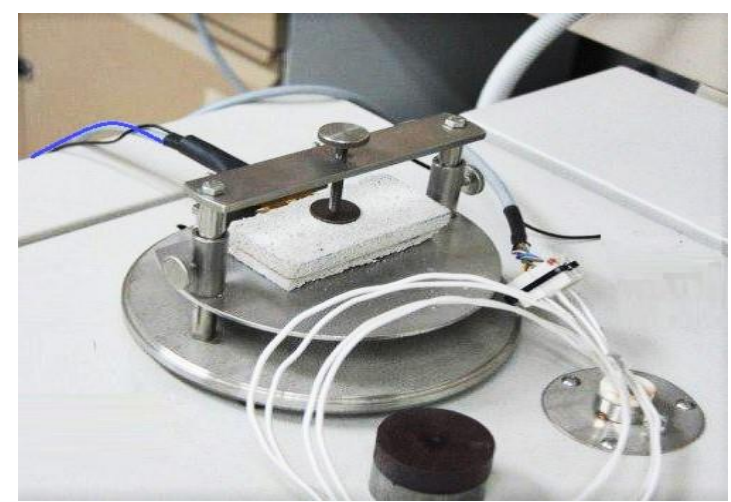

Fig. 2. Set up for the hot disk constant thermal analyser TPS $2500 \mathrm{~S}$

\subsubsection{SEM micrograph}

The FEI QUANTA 650 FEG ESEM was used to perform scanning electron microscopy (SEM) of some selected samples. A versatile scanning electron microscope is shown in Figure 3 . The researchers selected a $6 \%$ alkali-treated banana fibre from the raw fibre shown in Figure 1 . The single strand fibre was cut across its cross and then coated with gold for cross-sectional SEM investigation. Besides, composite ULFC test samples were cut to the size of $20 \times 20 \times 20 \mathrm{~mm}$ from the 28 days cured batch specimens and subjected to oven drying at the temperature of $70 \pm 5^{\circ} \mathrm{C}$ for 24 hours. The samples are well polished and dusted with a gas pressure blower before gold coating for the SEM test.

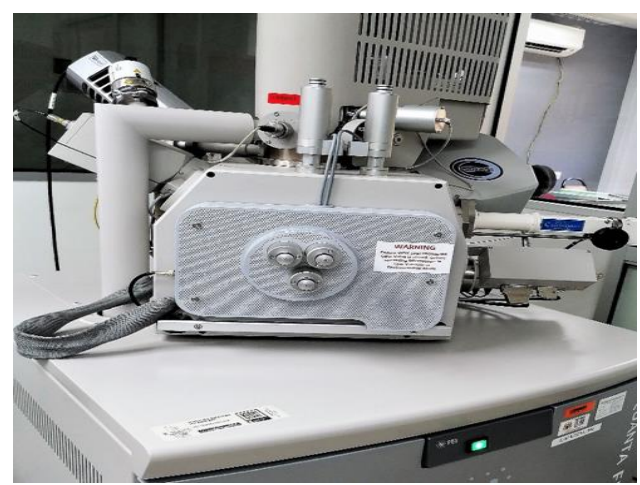

Fig. 3. Field emission scanning electron microscope - FEI QUANTA 650 FEG ESEM 


\section{Results and Discussion}

\subsection{Compressive Strength}

Figure 4 shows the results of the compressive strength of ULFC reinforced with alkali-treated banana fibre. The result depicts that as the curing age of the composites increases, the compressive strength increases. The compressive strength result was regular for all cementitious materials since plastic-wrapped curing was employed, moisture was retained during curing, thus continues production of C-S-H gel was enhanced. The compressive strength values for the $600 \mathrm{~kg} / \mathrm{m}^{3} \mathrm{ULFC}$ composites ranges between $0.8701 \mathrm{~N} / \mathrm{mm}^{2}-1.3604 \mathrm{~N} / \mathrm{mm}^{2}$ starting from the $0.00 \mathrm{CTR}$ batch to $0.55 \% \mathrm{BF}$ batch mix. From Figure 4 , results show that at all curing periods, fibre dosage of $0.35 \% \mathrm{BF}$ exhibits the highest compressive strength compared to all fibre dosages and the control. After the fibre dosage peak of $0.35 \% \mathrm{BF}$, the compressive strength decreases slightly at fibre dosages of $0.45 \% \mathrm{BF}$ and $0.55 \% \mathrm{BF}$. This percentage decrease in strength when the fibre dosage increases could result from fibre's balling effect during mixing attributed to excessive fibre addition in composites mix [11]. Compared to the control, the result indicates that compressive strength increases with an increase in fibre addition at all curing ages. The percentage increase in strength with respect to the control at 28 days curing age for batch mix $0.25 \mathrm{BF}, 0.35 \mathrm{BF}, 0.45 \mathrm{BF}$, and $0.55 \mathrm{BF}$ was reported as $13.85 \%, 24.48,4.82 \%, 1.64 \%$ respectively. This means that fibre addition of $0.35 \%$ BF gives the highest percentage increase in strength of $24.48 \%$, with a strength value of $1.3604 \mathrm{~N} / \mathrm{mm}^{2}$. This finding is similar to the work reported by Raj et al., and Xu et al., [11],17], who discovered that $0.3 \%$ coir dosage and $0.4 \%$ wood fibre is optimum in aerated alkali-treated fibre composites, respectively.

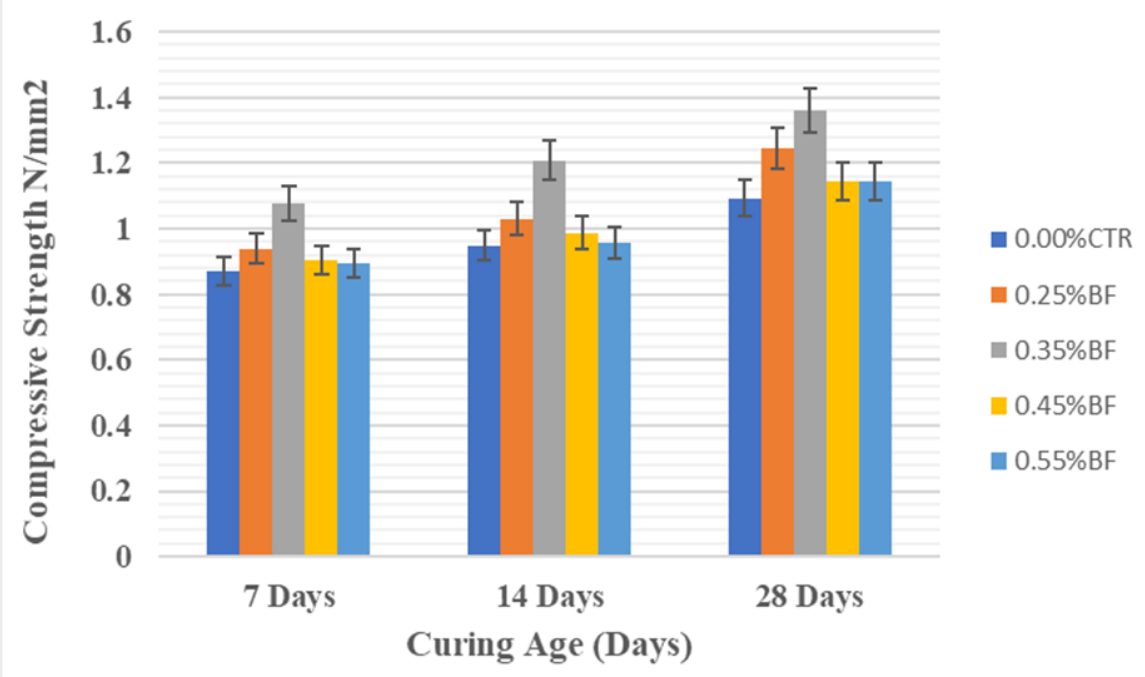

Fig. 4. Variation of compressive strength with different volume fraction of banana fibre

\subsection{The Density of ULFC Composite}

Table 6 shows the 28 days density and compressive strength of ULFC reinforced with alkalitreated banana fibre. The dry target density for all fibre addition was $600 \mathrm{~kg} / \mathrm{m}^{3}$. The unwrapped densities before oven curing range between $743-753 \mathrm{Kg} / \mathrm{m}^{3}$. The oven-dry density also ranges between $618-630 \mathrm{Kg} / \mathrm{m}^{3}$. It is interesting to note a slight increase in density than the control due to an increase in fibre addition. However, this slight increase in the density may not be because of the quantity of fibre added but because of the water quantity added to the mixtures with fibre addition. From Table 6 , the percentage increase in the dry density recorded with respect to control was $0.49 \%$, 
$1.13 \%, 1.82 \%$ and $1.94 \%$ for percentage fibre dosages of $0.25 \% \mathrm{BF}, 0.35 \% \mathrm{BF}, 0.45 \% \mathrm{BF}$ and $0.55 \% \mathrm{BF}$ respectively. These percentage increases are considered very negligible. The final dry density of $F C$ is mostly controlled by the quantity of foam added to the mortar mix, target density, and plastic density but not by any admixture added to it [18]. Hence, the major factor that controls the density of the ULFC reinforced with alkali-treated banana fibre was not the fibre dosage addition, but the volume of foam added during mixing. It has been reported that the wet or dry density of FC decreases with an increase in foam volume [19].

Table 6

Compressive strength and density of ULFC composites

\begin{tabular}{lllll}
\hline $\begin{array}{l}\text { Batch } \\
\text { code }\end{array}$ & $\begin{array}{l}\text { Compressive Strength } \\
\left(\mathrm{N} / \mathrm{mm}^{2}\right)\end{array}$ & $\begin{array}{l}\text { Unwrapped Density } \\
\left(\mathrm{Kg} / \mathrm{m}^{3}\right)\end{array}$ & $\begin{array}{l}\text { Target Density } \\
\left(\mathrm{Kg} / \mathrm{m}^{3}\right)\end{array}$ & $\begin{array}{l}\text { Oven dry density } \\
\left(\mathrm{Kg} / \mathrm{m}^{3}\right)\end{array}$ \\
\hline $0.00 \% \mathrm{CTR}$ & 1.0929 & 746 & 600 & 618 \\
$0.25 \% \mathrm{BF}$ & 1.2443 & 748 & 600 & 621 \\
$0.35 \% \mathrm{BF}$ & 1.3604 & 743 & 600 & 625 \\
$0.45 \% \mathrm{BF}$ & 1.1456 & 752 & 600 & 628 \\
$0.55 \% \mathrm{BF}$ & 1.1108 & 753 & 600 & 630 \\
\hline
\end{tabular}

\subsection{Sorptivity}

The result of sorptivity, otherwise known as the rate of water absorption of the ULFC, is given in Figure 5. The figure indicates that the rate of water absorption increases with an increase in exposure of composites surface to water. Although, in the first one-hour duration of exposure, more than half of the total water was absorbed for 24-hour exposure. This is similar to the work of Amarnath and Ramachandrudu [20], who reported a high water absorption within 30 minutes of exposure of sisal fibre composites FC to water.

Figure 5 also indicates that the capillary rise of water in foam concrete increases with an increase in percentage fibre addition into the composites. The figure clearly shows that the unreinforced ULFC (control) has the lowest rate of capillary rise in water, followed by $0.25 \% \mathrm{BF}, 0.35 \% \mathrm{BF}, 0.45 \% \mathrm{BF}$, and lastly, $0.55 \% \mathrm{BF}$. The percentage increase in the sorptivity at the 24-hour exposure to the control for $0.25 \% \mathrm{BF}, 0.35 \% \mathrm{BF}, 0.45 \% \mathrm{BF}$, and $0.55 \% \mathrm{BF}$ was $26.70 \%, 34.15 \%, 49.93 \%$, and $56.12 \%$, respectively. The highest percentage increase $(56.12 \%)$ in sorptivity was recorded for the highest fibre content of $0.55 \% \mathrm{BF}$ to the control.

This finding is in line with the work of Madhwani, Sathyan, and Mini; Raj et al., [21,11]. The increase in water absorption rate to the increase in fibre content was because of amorphous hemicellulose, lignin, pectin, and cellulose in natural fibre (refer to Table 3). Although the treatment of the fibre partially removes most of the fibre's amorphous components, such as hemicellulose and lignin, from the fibre surface, few components remain, and crystalline cellulose also absorbs a small percentage of water.

The presence of lumen in almost all-natural fibre is another contributing factor, as shown in the micrograph in Figure 9. Another reason for increase capillary rise in water is the average length of $50 \mathrm{~mm}$ fibre used in this study (refer to Table 3). This also provides continuity of water flow, breaking through isolated closed air pores and connecting them in the matrix (refer to figure 11). This is because water permeability does not only rely on porosity but a factor of paste phase and interconnection between them [21]. 


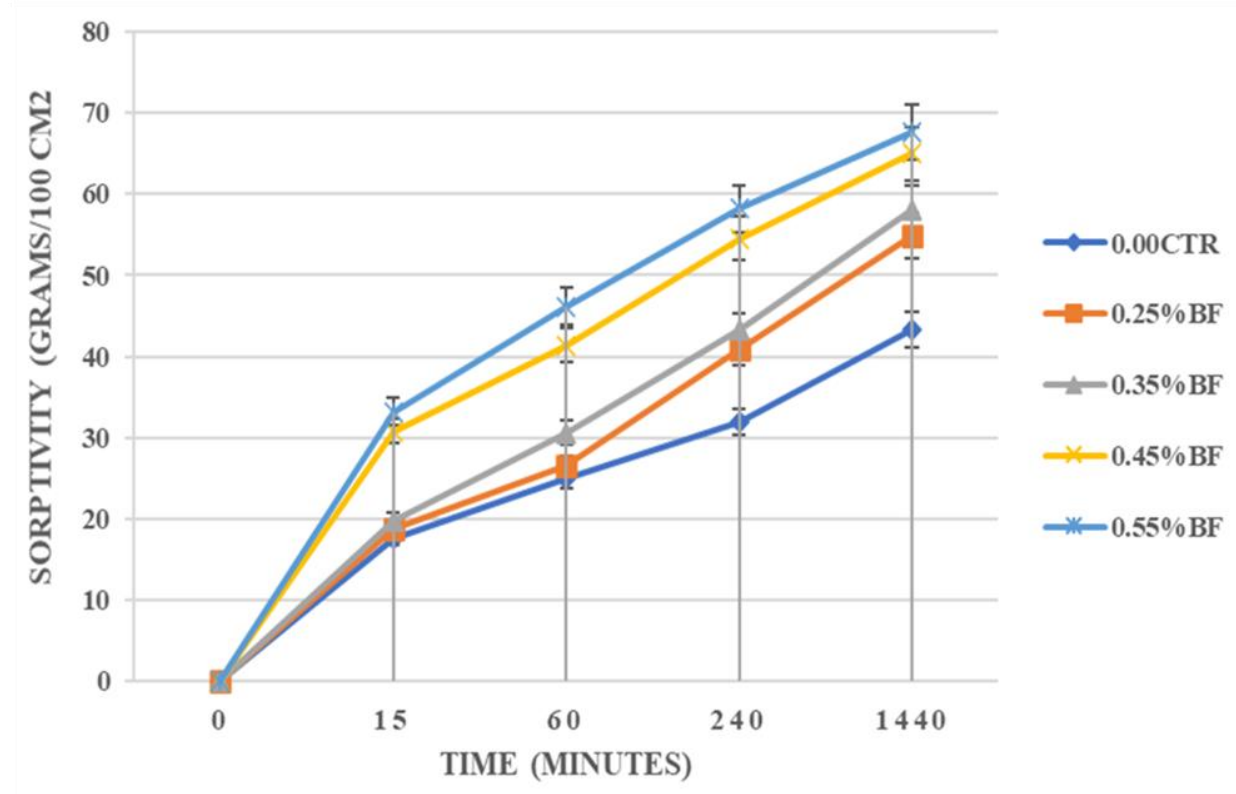

Fig. 5. Variation of the rate of water absorption with time

\subsection{Thermal Conductivity}

Figure 6 shows the result of the variation of thermal conductivity to the fibre dosage. The result indicates that for an equivalent alkali-treated fibre addition, the thermal conductivity of ULFC composites reduces. The ULFC reinforced with alkali-treated banana fibre dosage ranging from 0.25\%-0.55\%; the thermal conductivity reduces from $0.1889 \mathrm{~W} / \mathrm{mK}-0.1692 \mathrm{~W} / \mathrm{mK}$. Specifically, the thermal conductivity of the ULFC with the percentage alkali-treated banana content of $0.25 \% \mathrm{BF}$, $0.35 \% \mathrm{BF}, 0.45 \% \mathrm{BF}$, and $0.55 \% \mathrm{BF}$, was recorded by the composite as, $0.1889,0.1812,0.1713$ and $0.1692(\mathrm{~W} / \mathrm{mK})$ respectively. The percentage decrease in the thermal conductivity as the alkalitreated banana fibre content increases from $0.25 \mathrm{BF}, 0.35 \mathrm{BF}, 0.45 \mathrm{BF}$, to $0.55 \mathrm{BF}$ was respectively $3.08 \%, 7.03 \%, 12.11 \%$ to $13.17 \%$.

The highest percentage decrease of $13.17 \%$ was obtained when the highest dosage of $0.55 \mathrm{BF}$ alkali-treated banana fibre was incorporated into the ULFC. Reasons for the decrease in thermal conductivity as the fibre content increases are because of the porous nature of natural fibre and the lumen's presence, as shown in the SEM micrograph of fibre in Figure 9. This finding matched with Othuman Mydin et al.,; Raj et al., [8,11]. Other reasons for very low thermal conductivity in ULFC composites are the redistribution and creating a smaller uniform pore void due to the fibre's addition. This phenomenon resulted in the production of a more multiple isolated pore void than the control where there is no fibre addition, as illustrated in the micrograph of Figure 10 and Figure 11.

The quantity of heat transmitted through a unit thickness in a perpendicular direction to the surface of a unit area due to unit temperature gradients under a given condition is defined as the thermal conductivity of the ULFC. The lower the thermal conductivity of ULFC composites as the fibre increases, the higher the composites' thermal insulating property. The thermal insulating performance of the ULFC $(0.1949 \mathrm{~W} / \mathrm{mK}-0.1692 \mathrm{~W} / \mathrm{mK})$ composites improves tremendously compared to that of blocks $(0.6 \mathrm{~W} / \mathrm{mK})$ and bricks $(0.9 \mathrm{~W} / \mathrm{mK})$ used in building walls [19]. It is crucial to emphasise that strength is seriously compromised in the use of this ULFC. Therefore, because of the insufficient compressive strength (1.0929-1.1108) N/mm², this ULFC composite is suitable as infill material, especially in structural insulating panels (SIP). This will develop a novel SIP. The ULFC 
replaces the core reinforced with alkali-treated banana fibre reinforced instead of the traditional Expanded Polystyrene (EPS), Extrudable Polystyrene (XPS) Polyurethane Foam etc.

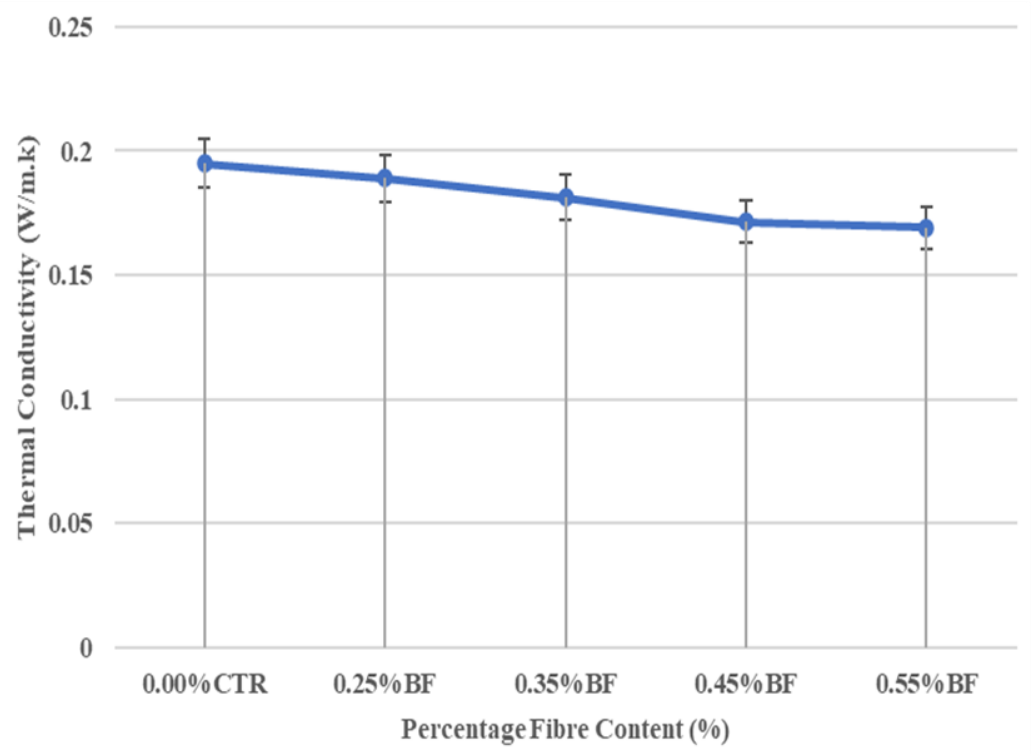

Fig. 6. Variation of thermal conductivity with different volume fraction of banana fibre

\subsection{Thermal Diffusivity}

The result of thermal diffusivity of ULFC composites reinforced with alkali-treated banana fibre composites is shown in Figure 7. The figure indicates that as the percentage of alkali-treated banana fibre increases, the thermal diffusivity decreases. This was as a result found for thermal conductivity of the ULFC composites. As fibre content of ULFC composites increases from $0.25 \% \mathrm{BF}$ to, $0.35 \% \mathrm{BF}$. $0.45 \% \mathrm{BF}$ to $0.55 \% \mathrm{BF}$, the thermal diffusivity decreases from $0.6141,0.5923,0.5069$ to $0.4684 \mathrm{~m}^{2} / \mathrm{sec}$, respectively. This resulted into getting a percentage decrease in the thermal diffusivity of $5.81 \%$, $9.16 \%, 22.25 \%, 28.16 \%$ as the fibre content increases from $0.25 \mathrm{BF}, 0.35 \mathrm{BF}, 0.45 \mathrm{BF}$ to $0.55 \mathrm{BF}$ respectively, and with respect to the control. The highest percentage decrease in the thermal diffusivity was obtained when the fibre dosage was maximum (0.55BF).

The incorporation of alkali-treated banana fibre into ULFC helps reduce the thermal diffusivity because of the low thermal conductivity of the plant-based fibre and cellulose, hemicellulose and lignin [11]. The fibrous nature of the fibre and lumen's presence further contributed to the porous fibre nature (Refer to Figure 9). The existence of high cellulose content (63.20\%), the alkali-treated banana fiber will instantly absorb water and have excellent wettability to enhance the composite's ULFC performance [22].

The thermal diffusivity of the ULFC material can be defined as the composite material's ability to conduct heat relative to the heat stored per unit volume. In other words, the thermal diffusivity of the ULFC is the measure of how fast heat can flow in the composite material.

Hence, if the heat flows within a composite's material very rapidly, the material is considered an excellent thermal conductor. In contrast, if the heat flows within a composite's material very slowly, the material is considered an excellent thermal insulator. In this case, the addition of the alkalitreated banana fibre into ULFC reduces or slows the rate of heat flow of the ULFC composites, thereby making it an excellent thermal insulator. As a result, the lower the thermal diffusivity value, the better the thermal insulating performance of the ULFC composites material. 
Hence, the addition of alkali-treated banana fibre from the dosage of $0.25 \mathrm{BF}-0.55 \mathrm{BF}$ resulted in a tremendous improvement in the thermal diffusivity of the ULFC from $0.6141 \mathrm{~m}^{2} / \mathrm{sec}$ to 0.4684 $\mathrm{m}^{2} / \mathrm{sec}$, respectively. The thermal performance has improved from $5.81 \%-28.16 \%$ with an equivalent increase in the alkali-treated banana fibre content from 0.25BF to $0.55 \mathrm{BF}$.

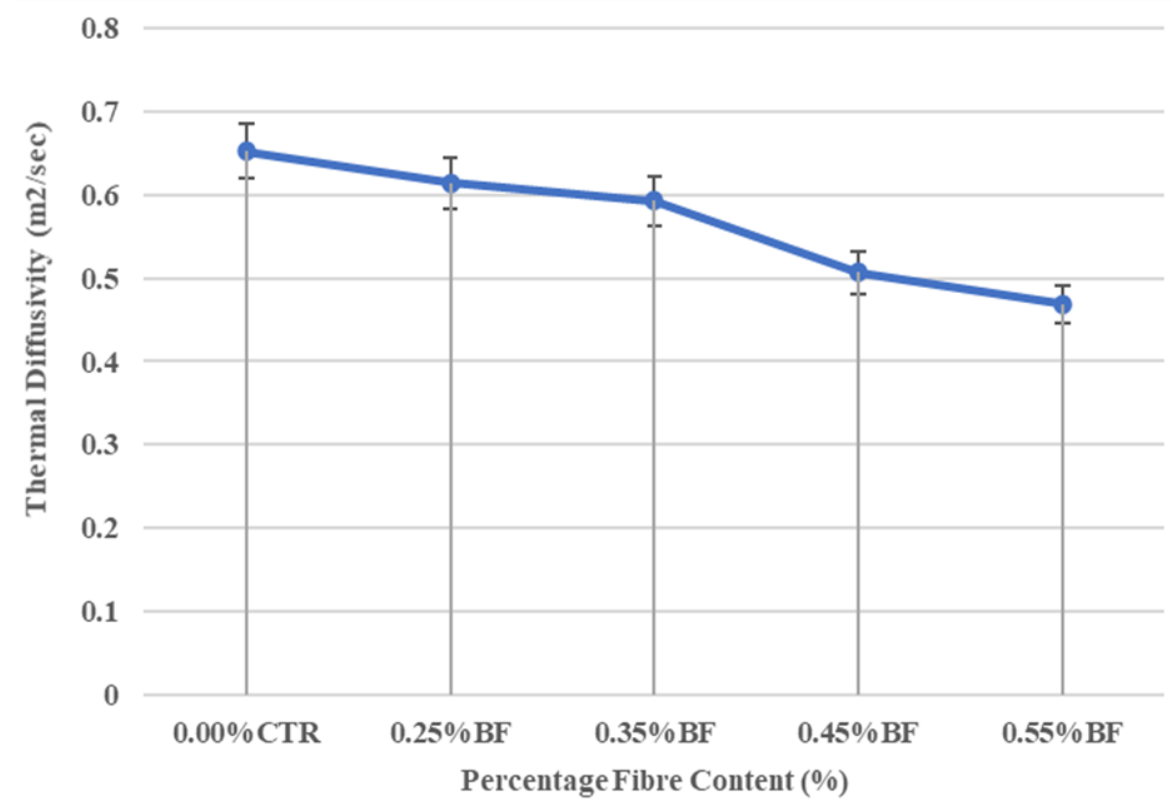

Fig. 7. Variation of thermal diffusivity with different volume fraction of banana fibre

\subsection{Specific Heat Capacity}

The result of the specific heat capacity of the ULFC reinforced with alkali-treated banana fibre is shown in Figure 8. The graph illustrates that as the fibre content of ULFC composites increases, so does their specific heat capacity. From the graph it is clear that as the fibre dosage increases, starting from the control, $0.25 \% \mathrm{BF}, 0.35 \% \mathrm{BF}, 0.45 \% \mathrm{BF}$, to $0.55 \% \mathrm{BF}$ the specific heat capacity of the composites also increases from $0.4007,0.4352,0.4679,0.5078$ to $0.5256(\mathrm{~J} / \mathrm{kg} \mathrm{K})$ respectively. This increase in specific heat capacity of the composite material resulted into a percentage increase of $8.61 \%, 16.77 \%, 26.73 \%$ and $31.17 \%$ with respect to $0.25 \mathrm{BF}, 0.35 \mathrm{BF}, 0.45 \mathrm{BF}$ and $0.55 \mathrm{BF}$ fibre content, in comparison to the control.

Thus, the highest percentage increase in specific heat capacity of $31.17 \%$ for the ULFC composites material was recorded when the fibre content was at the maximum value of $0.55 \% \mathrm{BF}$. This implies that when the alkali-treated banana fibre was added to ULFC, the material's specific heat capacity was tremendously improved. This improvement in the specific heat capacity of the ULFC composites materials was because of the vegetable fibre's organic nature, which encompasses hemicellulose, cellulose, lignin, and ash. The presence of these materials and their fibrous physical properties lead to an increase in the specific heat capacity of the composite ULFC [23].

The ULFC's specific heat capacity is defined as the ability of the composite material to absorb or release heat energy when the temperature rises or falls by one kelvin. The higher the value of the composite's specific heat capacity, the better the thermal insulation property of the material. Thus, the percentage increase in the specific heat capacity experienced by incorporating the alkali-treated banana fibre in the ULFC composites improves the composites' thermal insulation performance by increasing the material's specific heat capacity. 


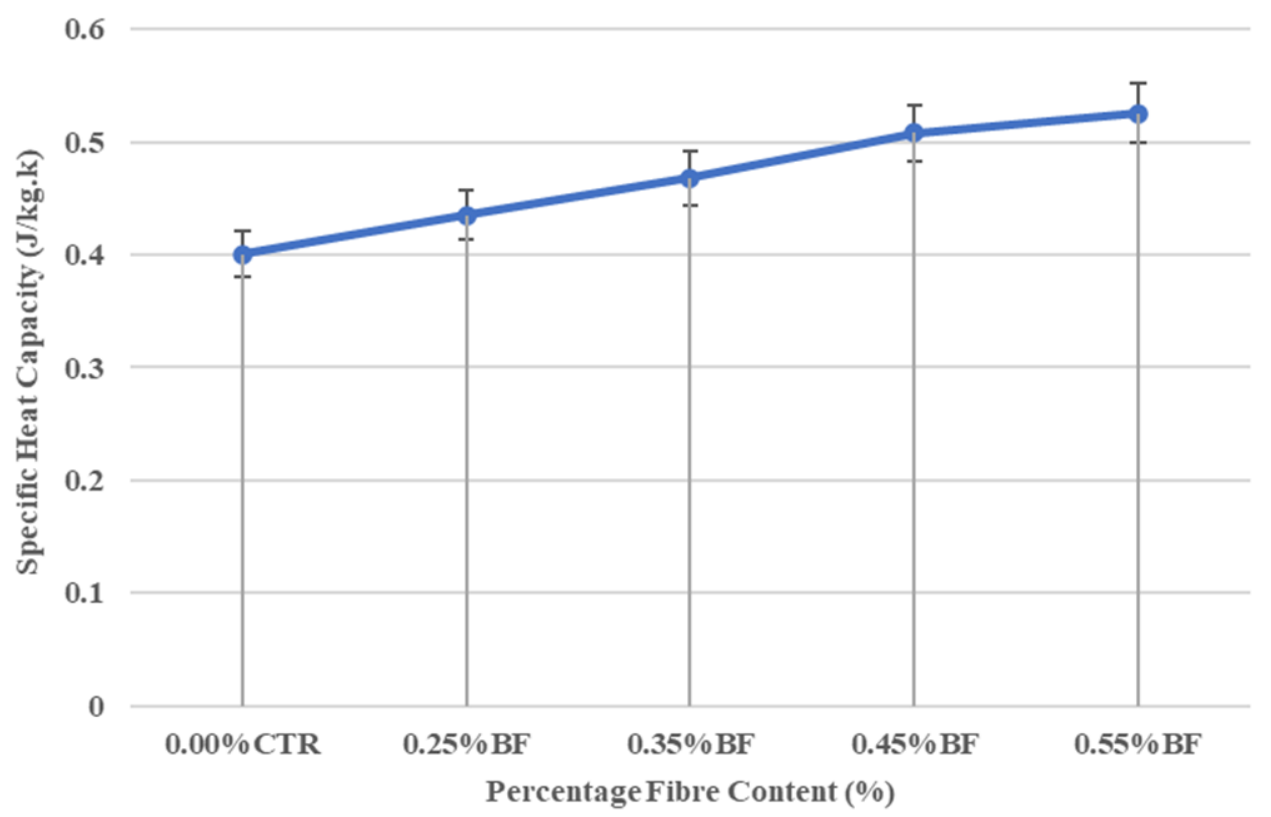

Fig. 8. Variation of the specific heat capacity with different volume fraction of banana fibre

\subsection{Microstructural Analysis}

Figure 9 depicts the morphology of a single strand alkali-treated banana fibre. It is clear from the figure that alkali-treated banana fibre is a multicellular, multi-layered fibre. A scaly and cellular structure characterizes the fibre. A single strand fibre, which is about 167um diameter (refer to Table 2), also contains multicellular bundles, in which each bundle is made up of several fibrils. Found at the centre of the bundled fibril is the lumen. The lumen is a hollow space responsible for the very lightweight nature of the fibre and high-water absorption. The lumen's presence is also responsible for high specific heat capacity and very low thermal conductivity and the ULFC composites' thermal diffusivity. In summary, it is because of the fibrous nature of the alkali-treated fibre and the presence of lumen that the resulting ULFC composites produced from it have an excellent thermal insulating property.

Figure 10 is the SEM micrograph of the unreinforced ULFC composites, i.e., the $0.00 \%$ CTR lightweight foam concrete. The SEM micrograph reveals the hollow micropore structure of a typical $600 \mathrm{Kg} / \mathrm{m}^{3} \mathrm{FC}$ very vividly. The air void structure and sizes for the plain control ULFC look uneven and large. This resulted in the overlapping of air voids, as shown in Figure 10, resulting in a considerable air pore. Unreinforced FC always creates large and uneven air-void systems, which leads to overlapping of the micropore [17].

Figure 11 shows the microstructure of a typical ULFC reinforced with $0.35 \%$ alkali-treated banana fibre. A close observation of the alkali-treated banana fibre ULFC indicates uniform air void systems and sizes. The air void looks similar in shape and size, with only a few overlapping micropores' incidences. Compared to figure 10, there are limited presences of massive air void systems, although there are few micro-cracks. It has been reported that the introduction of a small quantity of admixture or fibre into high porosity FC results in redistribution of the air void system from larger pore sizes too much smaller sizes with uniform void sizes [18]. This improvement created much smaller isolated air voids [24]. Isolated air void systems improve the thermal insulation property of concrete. Figure 11 also shows the presence of single-strand alkali-treated banana fibre in the ULFC composites microstructure. The fibre visibly links several air voids together, which has advantages in 
one area and disadvantages in the opposite direction. The advantages of long fibre linking several micropores are improvement in ductility, strength, post crack strength, fracture toughness, impact resistance, shrinkage resistance, etc.

In contrast, the linkages' disadvantages are increased water absorption, sorptivity, air and water permeability, etc. One of the significant advantages of this paper is the improvement in thermal conductivity since the fibre itself is porous and hollow. Hence, Figures 9, 10, and 11 clearly show us a system of high porosity FC composites reinforced with a fibrous, hollow scaly, and very light alkalitreated banana fibre that results in an improvement in the thermal insulating property and strength. However, the composites exhibited high water absorption properties due to their porous nature.

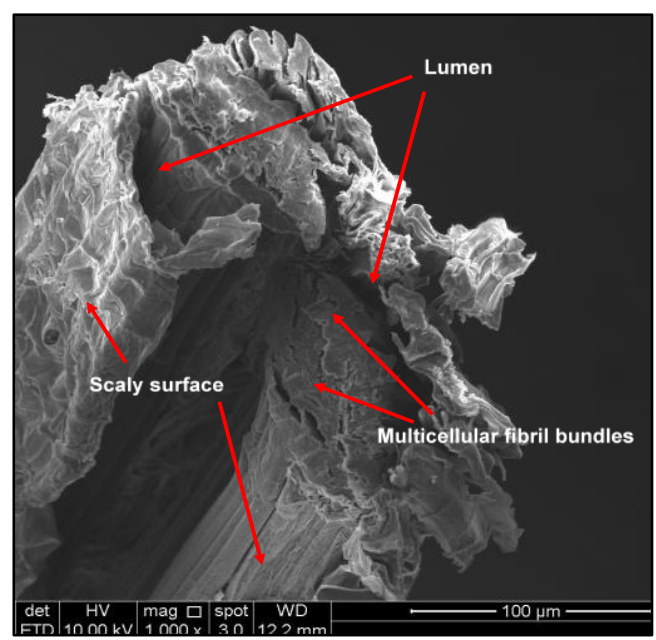

Fig. 9. SEM micrograph of a cross section of alkali treated fibre

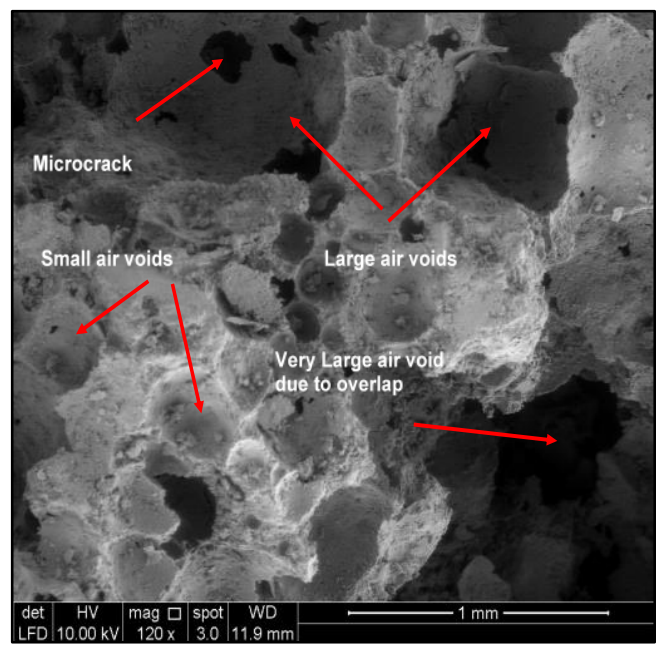

Fig. 10. SEM micrograph of control (0.00\%BF) ULFC 


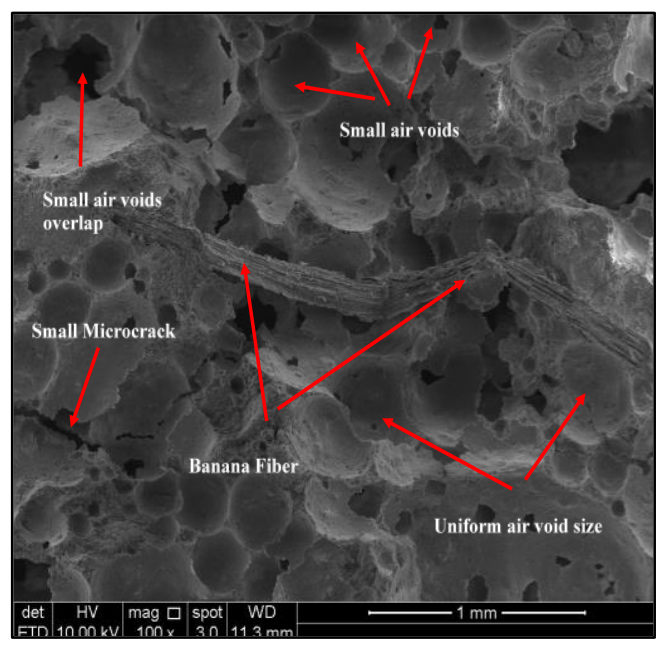

Fig. 11. SEM micrograph of $0.35 \% B F$ ULFC composite

\section{Conclusion}

In this study, the researchers investigated the strength, transport, and thermal performance of plain ULFC and ULFC reinforced with alkali-treated banana fibre. A morphological study using SEM analysis was undertaken to buttress the results from the study. The ULFC was reinforced with alkalitreated banana fibre at $0.25 \%, 0.35 \%, 0.45 \%$, and $0.55 \%$ to the mix's total weight volume. At the end of the study, the researchers developed a high porosity ULFC composite of $600 \mathrm{Kg} / \mathrm{m}^{3}$, with a very excellent thermal property and an improved low strength but with a high-water absorption rate. The summary of the finding is given in the outline below.

i. The optimum compressive strength of $1.3604 \mathrm{~N} / \mathrm{mm}^{2}$ was reached at 0.35 percent BF dosage, with an improvement in compressive strength corresponding to an increase in fibre dosage.

ii. The sorptivity test or capillary rise in water showed a tremendous increase in water absorption rate, increasing the percentage fibre dosage up to the highest dosage of $0.55 \% \mathrm{BF}$, recording a $56.12 \%$ water absorption rate.

iii. Thermal conductivity decreases with increase in alkali treated banana fibre dosage up to the maximum decrease of $13.17 \%$ at the fibre dosage of $0.55 \%$

iv. A similar decrease in thermal diffusivity with increase fibre dosage was exhibited up to the optimum decrease of $28.16 \%$ at the fibre addition of $0.55 \%$

v. With an equivalent increase in the fibre dosage up to the maximum of $0.55 \%$, specific heat capacity also increases to the optimum of $31.17 \%$.

vi. In all, an increase in alkali-treated banana fibre content increases compressive strength, water absorption, specific heat capacity, and a decrease in thermal diffusivity and thermal conductivity.

vii. It is therefore recommended that due to the very low compressive strength $\left(1.3604 \mathrm{~N} / \mathrm{mm}^{2}\right)$, high water absorption property, but excellent thermal insulation property $(0.1692 \mathrm{~W} / \mathrm{m} \mathrm{K})$, the ULFC reinforced with $0.55 \%$ BF should be used as an infill material (core) for hybrid walling system specifically as a partitioning insulating wall in a building.

viii. The ULFC composites could also be used in multi-layered insulating floor systems where a very good thermal insulating could be achieved.

ix. Further research effort should be conducted on the long-term durability property of ULFC reinforced with alkali-treated banana fibre in an alkaline cement composites system. 


\section{References}

[1] Elshahawi, Mahmoud, Alex Hückler, and Mike Schlaich. "Infra lightweight concrete: A decade of investigation (a review)." Structural Concrete 22 (2021): E152-E168. https://doi.org/10.1002/suco.202000206

[2] Brady, K. C., G. R. A. Watts, and M. Roderick Jones. Specification for foamed concrete. Crowthorne, UK: TRL Limited, 2001.

[3] Zhu, W. H., B. C. Tobias, R. S. P. Coutts, and G. Langfors. "Air-cured banana-fibre-reinforced cement composites." Cement and concrete composites 16, no. 1 (1994): 3-8. https://doi.org/10.1016/09589465(94)90024-8

[4] Savastano Jr, Holmer, P. G. Warden, and R. S. P. Coutts. "Brazilian waste fibres as reinforcement for cement-based composites." Cement and Concrete Composites 22, no. 5 (2000): 379-384. https://doi.org/10.1016/S09589465(00)00034-2

[5] Bilba, Ketty, Marie-Ange Arsene, and Alex Ouensanga. "Study of banana and coconut fibers: Botanical composition, thermal degradation and textural observations." Bioresource technology 98, no. 1 (2007): 58-68. https://doi.org/10.1016/i.biortech.2005.11.030

[6] Akinyemi, Banjo Ayobami, and Chunping Dai. "Development of banana fibers and wood bottom ash modified $\begin{array}{lllll}\text { cement mortars." Construction and Building Materials } 241 & \text { (2020): } 118041 .\end{array}$ https://doi.org/10.1016/i.conbuildmat.2020.118041

[7] Dhawan, Akshay, Nakul Gupta, Rajesh Goyal, and K. K. Saxena. "Evaluation of mechanical properties of concrete manufactured with fly ash, bagasse ash and banana fibre." Materials Today: Proceedings 44 (2021): 17-22. https://doi.org/10.1016/i.matpr.2020.06.006

[8] Mydin, MA Othuman, N. A. Rozlan, N. Md Sani, and S. Ganesan. "Analysis of micro-morphology, thermal conductivity, thermal diffusivity and specific heat capacity of coconut fibre reinforced foamed concrete." In MATEC Web of Conferences, vol. 17, p. 01020. EDP Sciences, 2014. https://doi.org/10.1051/matecconf/20141701020

[9] Mydin, Md Azree Othuman, Mohd Nasrun Mohd Nawi, Muhammad Arkam Che Munaaim, Noridah Mohamad, Abdul Aziz Abdul Samad, and Izwan Johari. "Effect of Steel Fibre Volume Fraction on Thermal Performance of Lightweight Foamed Mortar (LFM) at Ambient Temperature." Journal of Advanced Research in Fluid Mechanics and Thermal Sciences 47, no. 1 (2018): 119-126.

[10] Awang, Hanizam, and Muhammad Hafiz Ahmad. "Durability properties of foamed concrete with fiber inclusion." World Academy of Science, Engineering and Technology International Journal of Civil, Environmental, Structural, Construction and Architectural Engineering 8, no. 3 (2014): 269-272.

[11] Raj, Bhagyasree, Dhanya Sathyan, Mini K. Madhavan, and Amritha Raj. "Mechanical and durability properties of hybrid fiber reinforced foam concrete." Construction and Building Materials 245 (2020): 118373. https://doi.org/10.1016/i.conbuildmat.2020.118373

[12] Standard, E. "Cement-Part 1: Composition, specifications and conformity criteria for common cements." (2000).

[13] Standard, British. "Testing hardened concrete." Compressive Strength of Test Specimens, BS EN (2009): 12390-3.

[14] EN, British Standard. "Testing hardened concrete-Part 7: Density of hardened concrete." London: British Standard Institution (2009).

[15] ASTM International Committee C09 on Concrete and Concrete Aggregates. Standard Test Method for Rate of Water Absorption of Masonry Mortars1. ASTM International, 2015.

[16] Standard, I. S. O. "Plastics-Determination of thermal conductivity and thermal diffusivity-Part 2: Transient plane heat source (hot disc) method." ISO Standard (2008): 22007-2.

[17] Xu, Rongsheng, Tingshu He, Yongqi Da, Yang Liu, Junqi Li, and Chang Chen. "Utilizing wood fiber produced with wood waste to reinforce autoclaved aerated concrete." Construction and Building Materials 208 (2019): 242-249. https://doi.org/10.1016/i.conbuildmat.2019.03.030

[18] Amran, YH Mugahed, Nima Farzadnia, and AA Abang Ali. "Properties and applications of foamed concrete; a review." Construction and Building Materials $101 \quad$ (2015): https://doi.org/10.1016/i.conbuildmat.2015.10.112

[19] Mydin, MA Othuman, M. Musa, and AN Abdul Ghani. "Fiber glass strip laminates strengthened lightweight foamed concrete: Performance index, failure modes and microscopy analysis." In AIP Conference Proceedings, vol. 2016, no. 1, p. 020111. AIP Publishing LLC, 2018. https://doi.org/10.1063/1.5055513

[20] Amarnath, Y., and C. Ramachandrudu. "Properties of Foamed Concrete with Sisal Fibre." In Proceedings of the 9th International Concrete Conference. 2016.

[21] Elshahawi, Mahmoud, Alex Hückler, and Mike Schlaich. "Infra lightweight concrete: A decade of investigation (a review)." Structural Concrete 22 (2021): E152-E168. https://doi.org/10.1002/suco.202000206 
[22] Evi Sofia, Nandy Putra, and Ali Gunawan. "Evaluation of Indirect Evaporative Cooling Performance Integrated with Finned Heat Pipe and Luffa Cylindrica Fiber as Cooling /Wet Media." Journal of Advanced Research in Experimental Fluid Mechanics and Heat Transfer 3, no. 1 (2021): 16-25.

[23] Serri, Eravan, Md Azree Othuman Mydin, and Mohd Zailan Suleiman. "Thermal properties of Oil Palm Shell lightweight concrete with different mix designs." Jurnal Teknologi70, no. 1 (2014): 155-159 https://doi.org/10.11113/it.v70.2507

[24] Mydin, MA Othuman, N. Md Noordin, N. Utaberta, MY Mohd Yunos, and S. Segeranazan. "Physical properties of foamed concrete incorporating coconut fibre." Jurnal Teknologi 78, no. 5 (2016): 99-105. https://doi.org/10.11113/jt.v78.8250 